\title{
Expectations of and Concerns about Semester-long Study Abroad: A Case Study
}

\author{
Meihua Liu \\ Department of Foreign Languages and Literatures, Tsinghua University \\ Chengfu Rd., Qinghuayuan, Beijing, 100084, China \\ Tel: 86-10-62772459 E-mail: ellenlmh@yahoo.com \\ Wei CAI \\ Department of Foreign Languages and Literatures, Tsinghua University \\ Chengfu Rd., Qinghuayuan, Beijing, 100084, China \\ Tel: 86-10-62772421 E-mail: caiwei@mail.tsinghua.edu.cn
}

Received: 17-05- 2013

doi:10.7575/aiac.ijels.v.1n.1p.72
Accepted: 27-06- 2013

Published: 01-07- 2013

\begin{abstract}
The study reported in the present paper focused on the expectations of and concerns about the impending semester-long study abroad of students from a prestigious Chinese university. Data were collected via questionnaires and semistructured interviews. Analyses of 33 questionnaires and 15 semi-structured interviews yielded the following main findings: (1) the participants joined the exchange program for various motivations such as improving English, experiencing the host culture and broadening their views, and cultivating cultural awareness, (2) they held fairly high expectations from the exchange experience. They hoped to benefit from the experience in every aspect such as enhancing English proficiency, becoming more mature and independent, and interacting more effectively with people from diverse cultural backgrounds, (3) they, to varying degrees, believed that the exchange experience would be valuable to their academic and personal life and their future career, and (4) the majority participants had worries and concerns about their stay abroad such as culture shock, classroom participation, intercultural interaction, and language barrier. Consequently, the paper suggests an orientation or program should be provided by the home university to prepare students better for their study and life abroad prior to their sojourn.
\end{abstract}

Keywords: expectation, concern, study abroad

\section{Introduction}

Increasingly, tertiary-level students across the globe are gaining some form of international education. With the consolidation of the Erasmus program in Europe, stays abroad (SA) as contexts of language acquisition have become increasingly prominent in European tertiary education (Trenchs-Parera, 2009). The phenomenon in Europe runs parallel to a similar phenomenon in other parts of the world, where SA programs are now on the rise (Trenchs-Parera, 2009). In particular, East Asian students have increasingly become the majority of international students on university campuses (Xia, 2009). In Mainland China, the number of undergraduates who join exchange programs has also increased significantly as institutions of higher education sign more agreements to facilitate exchanges in recent years. Yet research on exchange students has been scarce. The present study aims to document the developmental trajectories (e.g., cultural, linguistic, identity, personal) of semester-long exchange students at a prestigious university in Beijing, China, with a focus on their expectations of and worries about the pending SA prior to the sojourn.

\section{Literature Review}

As more and more higher institutions and students become interested in SA, an abundance of research has been done on SA. Despite that some studies have found minimal or no effect of SA on students' acquisition of the target language (Collentine, 2004; Dewey, 2004; Díaz-Campos, 2004; Freed, So \& Lazar, 2003; Isabelli-García, 2010; Mora, 2007), the majority research has shown SA programs to be effective in fostering acquisition of second language skills (i.e., listening, reading, speaking and writing) (Hernández, 2010; Lafford, 2004; Lindseth, 2010; Pérez-Vidal \& Juan-Garau, 2011; Taguchi, 2008; Taillefer 2005; Yashima \& Zenuk-Nishide, 2008) as well as intercultural competence (Bataller, 2010; Cohen \& Shively, 2007; Jackson, 2011; Martinsen, 2011; Xu, Case \& Wang 2009). It has been claimed that students abroad become significantly more fluent (Lafford, 2004; Segalowitz \& Freed, 2004) and significantly increase their vocabulary after their experience in the foreign country (Dewey, 2008; Ife, Boix \& Meara, 2000; Lennon, 1990; Llanes \& Muñoz, 2009; Milton \& Meara, 1995).

Regan (2004) found that students who participated in a SA program "replicate the patterns of native speakers more closely than those speakers who learn in the classroom" (p. 337). Barron (2007) discovered that SA bettered the acquisition of upgrading in refusals of offers by 33 Irish learners of German. Allen (2010) concluded that SA 
experience enhanced language-learning motivation to varying degrees for participants with linguistically oriented motives for learning French. Serrano, Llanes and Tragant (2011) compared the performance of the students abroad with that of those in two intensive programs. The results showed that, after an equivalent period of exposure to the L2 in the two contexts, the students abroad outperformed the learners in the "at home semi-intensive" program in the post-test in some of the variables under study, namely fluency and lexical complexity. Nevertheless, the students' written and oral performance after an intensive course at home and after the equivalent time abroad was similar. Nevertheless, Sasaki's (2007) investigation of the changes in English writing behavior between 7 SA students and 6 at-home students revealed that only SA students improved their second language writing ability and fluency, that they made more local plans, and that they became more motivated to write better compositions in the target language. Pérez-Vidal and Juan-Garau's (2011) study of 55 Catalan/Spanish EFL undergraduates showed that SA benefits surpassed those benefits obtained as an effect of formal instruction in the domains of fluency, both oral and written, oral accuracy and formulaic language, and written lexical complexity.

Meanwhile, some studies, though very few, explored students' expectations and concerns about SA and the difficulties they encountered during their study abroad (Berry \& Williams, 2004; Koester, 1986; Wilkinson, 1998a, 1998b). Koester's (1986) large-scale quantitative study revealed that the students chose to work, travel and study abroad for various reasons and had diverse worries about going abroad, that foreign language majors might receive greater benefit from their international experiences than other groups of students, that the 6-12 month period might be the optimum time for the study, travel, or work abroad experience to increase the perceived positive impact. Wilkinson (1998a) found that the students suffered from 'stranger anxiety' during SA which might increase their reliance on their home culture. Berry and Williams (2004) investigated the difficulties encountered by 20 Hong Kong Chinese learners aged 12-18 studying in an educational environment where English was used as the first language. Although language was widely perceived as a problem for these learners, socio-cultural (e.g., cultural difference, differences in the school systems and school culture, etc.), and affective (e.g., anxiety, pressure from English and Chinese peers, etc.) aspects were also a cause of problems for the learners. These aspects were often interrelated and linked to the linguistic problems of the learners. The researchers believed that such learners should be given opportunities to voice their problems and needs either directly or indirectly, in the classroom or outside class time.

As reviewed, SA programs are very popular all over the world, but they have been the focus of interest of relatively few researchers (Freed, 1999; Huebner, 1998). Furthermore, most existing studies have examined language, pragmatic, or intercultural gains in groups of college students who spend varying durations abroad. Few studies have been concerned with students' expectations of and worries about SA prior to the sojourn, although some studies have revealed that students experience difficulties during SA such as anxiety and inability to communicate effectively with the local people (Berry \& Williams, 2004; Koester, 1986; Wilkinson, 1998b). The interest of collecting data from students in a prestigious university in Beijing, China, which had sent increasingly more students abroad on exchange programs in recent years, has motivated the study, part of which is reported in the present paper. The study has also been motivated by the dearth of research on SA in Asian contexts. The examination of Chinese learners' expectations of and concerns about the SA, and the changes in their linguistic and intercultural competence and identity while staying abroad can also throw some light on the variability that has been observed in previous research. The particular research questions for the present study are:

(1) What was the students' motivation to join the exchange program?

(2) What were the students' aims and expectations of the impending SA?

(3) What did they think of the coming SA?

(4) What were their worries and concerns about the SA?

\section{Research Design}

This paper reported on part of the results of a mix method investigation of whole person development as a result of semester-long study abroad, with a focus on students' expectations of and concerns about the impending SA prior to the sojourn.

Survey Respondents. Thirty one (1 male and 32 female) $2^{\text {nd }}$-year English majors, namely advanced EFL learners, from a prestigious university in Beijing answered the pre-sojourn survey in the present study. They all went abroad as exchange students during the first term (fall) of the academic year 2011-2012. With an age range of 18 to 21 and an average age of 19.697, 22 (66.7\%) of them had never been abroad, and the rest had traveled and/or studied abroad for 1 (the majority) to 6 months except that Gong had stayed in Japan for 7 years. Except that 8 students would go to Denmark, Germany, France, and Hong Kong, all the others would study in an English-speaking country.

Interview Respondents. 13 females of the 33 survey respondents, all from cities, participated in the semi-structured interviews prior to the sojourn. They would all go to English-speaking countries and the language of instruction of the courses they would take in their host universities would be English.

Except Deng, Ye, Tang, Yong, and Min, all the other interviewees had been abroad for varying durations of time. Three of the 13 interviewees had been to the host country (America) on an exchange program in the middle school, the others had never been to their host countries. Gong had lived in Japan for seven years since she was 5.5 and homestayed in America for 2 weeks during her middle school. After becoming a university student, she spent one week in South Korea on a program, discussing with students from different countries in Asia on various subjects such as politics, culture, 
education, and foreign affairs, and one month in Turkey on a program, working as a volunteer teacher of English to beginners there, respectively. Having stayed in different cultures made Gong "more desirable to know different places in the world and more confident to adapt to various environments". Xiao went to America on a summer camp for one month organized by her junior middle school, and traveled in European countries and Hong Kong with her relatives for a few days respectively later on. Han was invited to America as a visiting student in her senior middle school for a month; Gao toured in Hong Kong, Macau and Europe for about 10 days respectively during her high school, and joined an exchange program of her mother's school to Australia for half a month in college. Zhang stayed in Philippines for 10 days on a mass communication program in college; Peng stayed in America for 1 month on an exchange program in her senior middle school, and spent 15 days in South Korea for a debate camp later in college. Ning stayed in South Korea for 15 days on a program, traveled in Russia for a few days and spent 15 days in Britain on a program respectively in college. Li and Peng stayed in Spain on a Spanish culture and language program for 4 weeks in college.

Because of the experiences abroad, the interviewees improved their English, knew more about the local cultures (e.g., teaching and learning style, respect for privacy, etc.) (Gong, Ham, \& Peng), greatly enhanced their interest (Xiang \& Peng) in English, became (more) motivated (Xiao) to go abroad, became more confident and desirous to know different places (Gong), and became (more) aware of cultural and educational differences (Han \& Gao).

Instruments. The data reported in the present paper were collected through a survey and semi-structured interviews, as detailed below.

Pre-Sojourn International Exchange Survey. The 97-item mixed form Pre-Sojourn International Exchange Survey was adapted from that used in Jackson (2010) to gather data about the participants' background, L2 proficiency/use, intercultural contact/travel experiences, attitude towards home/host/other cultures/identity, aims/reasons for going on exchange, sojourn learning, self-perceived difficulties while abroad, self-perceived preparation of the coming study abroad, and personal comments about the program.

Pre-Sojourn Interview Guide. This 55-item Pre-Sojourn Interview Guide was adapted from that used in Jackson (2010) which involved the following aspects of the participants' ideas of the exchange program: background information and motivation to study abroad, goals and expectations of the program, current intercultural contact/intercultural communication skills, current identity, previous travel or study abroad, level of preparedness for SA, and future plans.

Procedure. Two months prior to their departure in late August, all the sojourners were invited to participate in the study, of whom 33 signed the consent form and filled in the survey online in 30 minutes 15 days later. After that, 13 of the survey respondents agreed to participate in semi-structured interviews, which were done during the following month. Each interview lasted about 1.5 hours and was audio-recorded.

Data Analysis. All the survey data were processed using SPSS, and the qualitative data (interview transcripts, openended survey questions) were subject to an 'open coding' approach (Grbich, 2007). To protect their privacy, a pseudonym was used for each interviewee when citing from her self-reports.

\section{Results and Discussion}

\subsection{Motivation to Study Abroad}

When asked about their motivation to join the exchange program, the interviewees voiced various reasons, with principal ones being to improve English and to experience the host culture and broaden their views.

Eight $(61.5 \%)$ of the interviewees joined the exchange program in order to improve English, especially spoken English. As English majors, they believed it a good chance to improve English by studying and living in an English-speaking host country. As Peng reported, “... I think as an English major, it is necessary to study the language in an Englishspeaking environment. I can learn something that can't be learned here, such as oral English, other aspects of English ..."

Six $(46.2 \%)$ interviewees decided to study abroad to experience the host culture and broaden their views. They held the view that as English majors, they should know more about the world and have a broader view, and that the best way to do it was to go abroad. "I think the main reason is to experience how people there study and live. It may not be academic, but it is related to everyday life. ..." (Zhang) and "... When studying abroad, we can better experience the native culture and their life" (Li).

Two (15.4\%) interviewees respectively reported that the program would increase their chance for future graduate study abroad, make their resumes more competitive for higher education and/ or in the future job market, help them better know the world and their counterparts of other nationalities, ethnicities and cultures, and enable them to experience the higher education system of the host country and test whether they could study abroad in the future. They believed that joining an exchange program would make them more competitive when applying for graduate study abroad, especially if they could have a recommendation letter from a professor in the host university. They also claimed that study abroad for one semester would accumulate their experiences, making their resumes more competitive for higher education and/or in the future job market. As Min said, "I think it is very different to live and study in a different university, especially in a different culture and country. This will be a huge help when studying abroad or looking for a job in the future." Meanwhile, two (15.4\%) interviewees maintained that exchange study was an indispensable part of English learning, though it was not a requirement at their home university. Two (15.4\%) interviewees simply followed others to 
join the exchange program. They reported that they could not find a reason to stay at home since "most of my class will go abroad as exchange students. I have to follow them, otherwise, I would be lonely" (Li).

Finally, individual reasons for going abroad varied such as cultivating cultural awareness, having more chances, the host university ranking high and being (very) good, personal interest, experiencing the educational system in the host country, and asking for a recommendation letter to apply for graduate study abroad in the future. For example, Min commented that she decided to go abroad “... in order to have another kind of experience. In whatever situation, it is a good experience to live and study in a different country, live alone and deal with people with various backgrounds".

\subsection{Aims and Expectations}

Meanwhile, the survey respondents were asked to rate the items about their aims and expectations of study abroad on a scale of 1 (not at all important) to 5 (extremely important). The results are summarized (in the descending order) in Table 1.

Table 1. Aims and Expectations of Study Abroad $(\mathrm{N}=33)$

\begin{tabular}{|c|c|c|c|}
\hline & & $\mathrm{M}$ & SD \\
\hline 4. & To enhance my proficiency in a second or foreign language & 4.48 & .67 \\
\hline 2. & To become more mature and independent & 4.39 & .66 \\
\hline 17. & To experience life in another culture & 4.39 & .75 \\
\hline 7. & To travel and see many new places & 4.39 & .83 \\
\hline 24. & To become a more cosmopolitan, global citizen & 4.36 & .70 \\
\hline 5. & To make friends with people from other cultures & 4.33 & .78 \\
\hline 1. & To enhance my knowledge and skills in my discipline (major) & 4.27 & .76 \\
\hline 13. & $\begin{array}{l}\text { To increase my ability to interact effectively with people from diverse } \\
\text { cultural backgrounds }\end{array}$ & 4.24 & .90 \\
\hline 21. & $\begin{array}{l}\text { To develop my ability to look at problems/ situations from different } \\
\text { perspectives }\end{array}$ & 4.21 & .70 \\
\hline 10. & To gain exposure to a second/ foreign language in daily life & 4.15 & .80 \\
\hline 20. & $\begin{array}{l}\text { To increase my ability to communicate in the language used in the host } \\
\text { community }\end{array}$ & 4.15 & .87 \\
\hline 23. & To become more self-confident & 4.00 & .83 \\
\hline 8. & $\begin{array}{l}\text { To improve my practical, academic skills (e.g. writing essays, giving oral } \\
\text { reports, doing project work, etc.) }\end{array}$ & 3.97 & .88 \\
\hline 12. & To increase my understanding of MY OWN culture, identity, and values & 3.97 & .98 \\
\hline 18. & To increase my level of comfort with people different from myself & 3.97 & .92 \\
\hline 22. & $\begin{array}{l}\text { To add diversity to my academic program (e.g. take courses not offered at } \\
\text { Tsinghai) }\end{array}$ & 3.91 & .91 \\
\hline 6. & To gain valuable experience for my future career & 3.88 & .93 \\
\hline 16. & To increase my understanding and appreciation of other peoples and cultures & 3.82 & .95 \\
\hline 3. & To enhance my résumé and increase job opportunities & 3.76 & .90 \\
\hline 14. & To increase my understanding of international issues and events & 3.73 & .98 \\
\hline 19. & To enhance my critical thinking skills & 3.61 & 1.03 \\
\hline 9. & To challenge myself intellectually & 3.33 & 1.11 \\
\hline 11. & To have fun & 3.27 & 1.13 \\
\hline 15. & To help me develop leadership skills & 3.27 & 1.10 \\
\hline 25. & Other, please specify: & & \\
\hline
\end{tabular}

As noted from Table 1, the score for each item ranged from 3.27 to 4.48 , well above the item midpoint 3, meaning that the respondents held fairly high aims and expectations of the coming SA. They hoped to benefit from the SA in every aspect such as enhancing résumé and becoming more competitive in future job market and future career (item 3), improving practical and academic skills (item 8), better understanding their own culture, identity and values (item 12), better understanding international issues and events (item 14), developing leadership skills (item 15), better understanding and appreciating other peoples and cultures (item 16), increasing people skills (item 18), and enhancing critical thinking skills (item 19). In particular, they held that study abroad (SA) would enhance their proficiency in a SL/FL (item 4, M = 4.48) and knowledge and skills in their discipline (item 1, M = 4.27), help them become more 
mature and independent (item $2, M=4.39$ ), enable them to travel and see many new places (item 7, $M=4.39$ ) and experience life in another culture (item 17, M =4.39), help them become more cosmopolitan, global citizens (item 24, $\mathrm{M}=4.36$ ) and more confident (item 23, $\mathrm{M}=4.00$ ), help increase their ability to interact effectively with people from diverse cultural backgrounds (item 13, $\mathrm{M}=4.24$ ) and to communicate in the language used in the host community (item $20, M=4.15)$, help develop their ability to look at problems/situations from different perspectives (item $21, \mathrm{M}=4.21$ ), enable them to make friends with people from other cultures (item 5, M=4.33) and to gain exposure to a SL/FL in daily life (item 10, M=4.15).

Similar to their motivations to join the exchange program, the most important aims and expectations the interviewees held for the SA were: (1) to improve English (8/61.5\%), (2) to self-experience and understand more about the local culture $(5 / 38.5 \%)$, and (3) to develop their ability to live alone $(4 / 30.8 \%)$ during the SA.

To improve English was generally considered to be the most important and the biggest aim of the SA, as evidenced by Li's words,

"I think to English majors, the most important is to improve English. ... People seldom use English in daily life [in Beijing]. When abroad, we will have to use the language every day. We may need to use slangs, names of various articles in daily life. Our oral English will be enhanced. Also, we will take the same courses as the native speakers, doing lots of assignments, reading a lot, writing a lot, and communicating a lot. Our academic English will be improved as well".

To self-experience and understand more about the local culture was the next important expectation of the SA to them. "I think the most important is to understand how an American lives. Or if I am in America, how I will live there, ... I think the most important may still be to experience how they live" (Zhang). Yong wanted "... to go through everything myself, experience everything and adapt to the local life". Gong expected "... to understand more about their culture. Because I'm interested in translation, I want to learn more about their thinking and ideas such as common senses".

Meanwhile, they hoped to achieve one or more of the following: make more friends, to test whether they could live in America so that they could decide whether to go on with their postgraduate study there, to experience how it was like when studying abroad, to travel, to communicate with different people, which often offered one a different perspective, to develop the ability to deal with emergencies, to learn to drive there, to become more academic, to get a recommendation letter, to gain a different experience, and to learn what could not be learned at their home university such as courses on globalization and cultural conflicts, conflict management and gender studies. For example, Min reported hoping "... to gain more experience. It [studying abroad] will be my estate when I apply for jobs or graduate study in the future". As such, their aims and expectations of the impending SA were largely consistent with those of the survey respondents.

To achieve these aims, 4 (30.8\%) interviewees reported that they would try to do their best in each course, actively previewing, reviewing, and participating in classroom discussions and making the best of course teachers' office hours; the others expressed that they would try to make the best of their time abroad.

\subsection{Self-perceived Impact of the Exchange Program}

Thirteen (39.4\%),16 (48.5\%), and $4(12.1 \%)$ of the survey participants believed that the coming SA would be very valuable, valuable, and somehow valuable respectively for their academic life. Twenty two (66.7\%), 20 (30.3\%), and 1 (3\%) of them reported that it would be very valuable, valuable, and somewhat valuable respectively for their personal life, and $4(12.1 \%), 22(66.7 \%)$, and $7(21.2 \%)$ of them respectively held that it would be very valuable, valuable, and somewhat valuable for their future career.

Similarly, the interviewees also reported the coming SA to be (very) valuable to their academic, personal and future professional life. They claimed that they would gain the following from the coming exchange program, as found in Koester (1986): (1) becoming more fluent in using English (Tang), (2) developing an overall view of the world and values (Tang \& Gong), (3) expanding their horizons (Yong, Zhang, Peng, \& Li), (4) expanding academic knowledge (Yong \& Gao), (5) becoming mature (Min), (6) becoming better at learning (Min), (7) becoming more independent and strong-willed (Han \& Deng), (8) setting short-term goals (Han), (9) becoming more outgoing (Gao, \& Gong), (10) finding out future interests (Gao, Peng, \& Ning), (11) knowing more about foreign cultures (Gong \& Li), (12) enriching life experiences (Zhang \& Ning), (13) improving people skills (Peng), and (14) finding a chance to travel around and relax in the host countries (Li). For example, Min confided that "... Since it will be more demanding and challenging to study in the host university, coupled with the fact that I will have classes with the local students, my learning ability will be challenged and enhanced thereafter". And Deng believed that "it [study abroad] will be the most important experience in my four-year college life. It offers me a totally different living environment. ... I can do something I dare not. ...".

In particular, these interviewees maintained that the SA could enable them to achieve what they could not achieve during their undergraduate study at their home university: (1) the English-learning environment (4/30.8\%) because "though we are English majors here, we seldom use English" (Xiao) and "We will become more confident and fluent when using English in the host country" (Tang), (2) self-experience of the local education system $(1 / 7.7 \%)$, (3) a different experience $(1 / 7.7 \%)$, as reported by Yong

"I think it will be a different experience. I can experience nothing except study here. In fact, I have done many things that I had never done before during the past two months of this term such as applying for the visa, having 
documents notarized, and requesting past academic reports and bank statements. Let alone study abroad for one term. I think I can handle many things after having gone through all of these",

(4) the ability to live alone (1/7.7\%), as explained by Min,

"I think it is the ability to live alone. I'll be completely independent in the real sense. I need to deal with everything such as study, daily life and various activities there alone. Though I am fairly independent here, I still have my class, roommates and mentor to turn to. I am actually not all on my own all the time here. But it will be totally different when I am abroad. And I will live in that entirely different environment, which cannot be achieved here",

(5) a new perspective about study, life and the world $(1 / 7.7 \%),(6)$ greater confidence to speak in the public $(1 / 7.7 \%)$ in that

"when speaking to the public here, I feel OK because I know many of the audience. But when I am abroad, I know few of the people there, I will feel shy and timid. I hope I could become braver and more confident to speak in public when I am abroad" (Deng),

(7) a better understanding of the local culture, the target language, and the difference between the local culture and Chinese culture $(1 / 7.7 \%)$, (8) a better understanding of the research methods used in the host university $(1 / 7.7 \%)$, as Zhang said, "I think it is the way how they do research. ... Although our department has many foreign teachers who can teach us the ways and methods they had been taught, they are not the same. And our system is different from theirs, thus our teaching and learning processes are different as well. I can learn how they teach and learn and how they do research. This is what I can't get here", (9) a strengthened sense of identity of their own culture (1/7.7\%). "I think my sense of identity of my own culture will be strengthened when I am abroad. I may not value much our culture here. But if I am abroad, I will be more sensitive to it and value it more. ... When I am abroad, I will meet different people and know how they see China. I will gain lots of different information" (Peng), and (10) a different way of thinking (1/7.7\%). “... When I am abroad, I may communicate with different people who are talented and brilliant, which may influence my way of thinking" (Ning).

Consequently, they all believed that the coming experience abroad would help them realize their dreams in one way or another. The reasons were as follows: (1) an experience abroad itself was useful, (2) a recommendation letter from a professor in the host university would be highly appreciated, (3) it would be an estate to work in a multinational company, (4) it would help them find out what they were really interested in and where to study for it, (5) it would help them find out whether they could fit a foreign environment or want to live abroad, (6) it would increase their academic knowledge such as ideas and methods about doing research.

\subsection{Worries and Concerns about the $S A$}

\subsubsection{Level of preparedness for and general worries about SA}

Sixteen $(48.5 \%)$ of the survey respondents reported to be well prepared, $16(48.5 \%)$ somewhat prepared, and $1(1 / 13)$ not prepared for the coming SA. Likewise, Deng, Gong, Gao and Zhang thought they were prepared both psychologically and physically, which might be because of their "past experiences" (Gong \& Gao) and "personality"” (Deng \& Zhang). The other interviewees reported that they were not prepared yet, either psychologically or physically, though they had gone through or were in the process of all kinds of formalities/procedures such as visa application, booking tickets, looking for accommodation, course selection, life necessities, cooking, and travelling. They hoped they would take in more information after their final-term exams were over, which would still center on the abovementioned issues.

Except that there was an informal meeting where a professor of the Department of Foreign Languages and Department in charge of exchange programs and the students who had previously joined the exchange program were invited to talk and discuss with the students who would go abroad as exchange students, no formal orientation was organized for these students either by their home university or department, which was disappointing to all the interviewees except Ye. To Ye, she could not gain much useful information from the talks with Chinese students or teachers and there would be an orientation in her host university which would tell her what to do during her stay there. All the others believed it would be useful to have an orientation which could offer them the following information: (1) what partner universities available for them to go to on the exchange program, (2) what courses to be selected and what credits could be transferred to the home university, (3) where to live in the host university, (4) what life was like in the host university, (5) what to bring (e.g., textbooks, clothes, etc.) to the host university, and (6) how to apply for the visa, etc. Nevertheless, these interviewees were more or less (more) familiar with the whole procedure of going abroad on the exchange program because of the following reasons: (1) they, actually the whole class, were involved in writing a guide book on the exchange program since it first started at the University as a quality development project during the first term of 2011, and (2) they generally actively sought communication and advice from those who had been to the host universities in previous years or their middle school students and friends who were studying and/or living in the host universities/cities. It might be a (extremely) different case for those who did not participate in such a program when an orientation could make a big difference.

As they prepared more and more about going abroad, Yong and Deng became more and more confident in that they had handled many things they had never done before. The others just came to look forward to it more. 
Even so, they had various worries and concerns about the coming SA, as reported in Koester (1986) and Takai (1989). For example, Tang, Han and Li were concerned about security, and Deng worried about safety if she happened to travel to a place full of black people (interestingly, she knew it was a bias yet she still worried about it, which in turn motivated her to go to that place to see what the truth was). Zhang had fear of uncertainties in that she was not sure of what might happen. Ye worried about cost because she did not want to ask for money from her parents. She and Tang also worried about having difficulty communicating with others due to language barrier. Tang, Zhang, and Peng were afraid that they might not be able to adapt to the local life easily. As far as Peng knew, American students attended lots of parties and other entertainment activities, she was thus in a dilemma of whether to continue to study hard as she had been at her home university, which she thought would be weird to the local students, or to behave more like the local students, which would be unacceptable to herself. Xiao was afraid of being not quick-witted and being cheated due to inadequate life experiences. Xiao, Gong, and Deng feared that they might be unable to compete with the local students due to the fact that they were not native speakers. Han worried about being discriminated against; Gong, Gao and Ning worried about life in their host universities such as gaining weight, booking plane tickets and planning travel.

\subsubsection{Self-perceived Biggest Challenges during SA}

When asked about the biggest challenges they would encounter during the SA, the majority of the survey respondents identified culture shock (21/63.6\%), interacting with people from other cultures (12/36.4), and participating in class (e.g., discussions) $(12 / 36.4 \%)$ as three most difficult challenges. Next came personal safety and security $(9 / 27.3 \%)$, language barrier $(8 / 24.2 \%)$, heavy workload $(8 / 24.2 \%)$, and homesickness $(8 / 24.2 \%)$. Seven $(21.2 \%)$ of the survey respondents also believed managing finances to be a big challenge, $3(9.1 \%)$ of them worried about accommodation, and $1(3 \%)$ was concerned with racial discrimination and making money respectively.

As such, culture shock was generally considered to be a great challenge to the students while abroad. Surprisingly, it was not a serious problem to the interviewees. Tang, Yong, Gao, and Li explicitly recalled that they had encountered culture shock when they were abroad or with foreigners before. For example, Gao still deemed that the Australians should not have made such a big fuss over the noises the Chinese middle school students made outside their hotel rooms. The others either held the view that culture shock was not a big deal or that there was actually no cultural differences or conflicts but differences in lifestyles. After all, as English majors, they had been in (close) contact with the cultures of different English-speaking countries, in addition to the language. Consequently, they were generally psychologically, sometimes unconsciously, prepared for cultural differences and open to new cultures. If they would encounter culture shock, Tang and Min would "respect them but express her own ideas. She can watch and see but will not participate"; Li and Ning would remain detached and tolerant; Ye would try to do as Romans do; Tang, Deng, and Peng would try to discuss the shock with both Chinese and American students or friends to understand why they felt shocked or shocked others. Han and Gao would also try to explain why the shock happened and be objective. If the shock meant bias against China or the Chinese, Ning and Deng would try to defend for them.

Homesickness was not considered a big issue to the interviewees either. Since having been (far) away from home since junior middle school, none of the interviewees thought they would be much homesick when abroad. If they really were, they would regularly call their parents and friends at home, chat and/or video talk with them online.

Meanwhile, 7 interviewees (Ye, Zhang, Peng, Ning, Min, Han, \& Gao) argued that the biggest challenge when abroad would be study because it would be more demanding and the professors expected more of the students in the host universities (Ye \& Zhang) and that it might be hard to catch up with the native speakers (Peng). Ning also reported that adapting to the local life would be a great challenge. $\mathrm{Li}$ and Min held that language and customs would be their great challenges when abroad. As they explained, they might not be able to use the words frequently used by the native speakers in their daily life, which might impede communication. Min, Gong and Han rated the ability to live alone as another big challenge to them. Though having been abroad several times, Gong was well looked after by her own parents or the host families each time. Thus she worried about taking care of everything alone. To Min, she had never been independent in her life in the real sense since she could always turn to her parent, mentor and classmates for help in China. Thus, to live alone would be a great challenge to her because she "will have to handle everything all on her own in the real sense". Han was even afraid of being alone and thus she would try to make new friends and call her parents frequently. Yong worried about knowing nothing about the host university or city, though she actually knew something. Tang believed the greatest challenge came from her own psychological beliefs or worries. Deng worried about how to deal with it if she felt frustrated when abroad such as being unable to meet course requirements or take part in a conversation, or being prejudiced.

\section{Conclusions and Implications}

The study reported in the present paper focused on students' expectations of and concerns about the impending SA. Analyses of the triangulated data yielded the following conclusions.

First of all, the participants joined the exchange program for various motivations such as preparing for future postgraduate study and future career and cultivating cultural awareness, the most important of which were to improve English, especially spoken English and to experience the host culture and broaden their views. Accordingly, they held fairly high expectations of the SA. They hoped to benefit from the SA in every aspect such as enhancing résumé and becoming more competitive in future job market and future career, with the highest expectations being to enhance their proficiency in a SL/FL and knowledge and skills in their discipline, to become more mature and independent, to travel and see many new places, to experience life in another culture, to become more cosmopolitan, global citizens and more 
confident, to interact more effectively with people from diverse cultural backgrounds, to make friends with people from other cultures, and so on.

They believed they would gain a lot from the SA and achieve what they could not during their undergraduate study at their home university such as the English-learning environment, self-experiencing the local education system, and the ability to live alone, and so on.

All the participants, to varying degrees, reported that the exchange experience would be valuable to their academic, personal, and future professional life. They believed that they would become more fluent in using English, develop an overall view of the world and values, expand their horizons, become more (more) mature, to name a few, after the SA. It would help them realize their dreams in one way or another as well.

Most participants were prepared for the coming SA to varying degrees, however, they still had worries and concerns about their stay abroad such as uncertainties, communication difficulties, and the incompatibility of their learning style with the local students'. The biggest challenges for them while abroad would be culture shock, classroom participation, intercultural interaction, security, language barrier, heavy workload and homesickness.

As such, the participants held fairly high expectations of and had worries and concerns of various kinds about the SA. It was possible that high expectations might result in some worries about the SA. Coupled with the fact that there was no orientation available prior to the sojourn at their home university, it might be better for the home university to provide orientation about the life and study at the host university, which could help students set (more) realistic goals, become (more) aware of the similarities and differences in life and study between home and abroad, become (more) confident about how to prepare for the SA. As found in DeKeyser's (2010) study of 16 U.S. students of Spanish during a 6-week program abroad, the promise of study abroad remained unfulfilled without adequate preparation in the form of proceduralized or at least declarative knowledge of the second language grammar. Thus, to better prepare students achieve their aims and expectations of the SA, it is beneficial to open a course to prepare students going abroad, as suggested by a number of other researchers as well (Barkhuizen \& Feryok, 2006; Jackson, 2011; Jarvis \& Stakounis, 2010). Jarvis and Stakounis (2010) recommended that work in some areas could begin on English language programs in the home country well before students went abroad, such as shaping and managing expectations and discussing the notions of English as an international language. Barkhuizen and Feryok's (2006) study well identified the importance of preparing students for a SA program prior to the sojourn.

"Such preparations go well beyond the usual advice about clothing ... and travel documents. The home institution

... had clearly spent considerable time encouraging the participants to make the most of their time, and exploring ways in which to do so, .... The participants felt that they were expected by their home institution to participate in new experiences, and so they did, often hesitantly at first, but with increasing enthusiasm" (Barkhuizen \& Feryok's, 2006, p. 131).

Jackson (2004) suggested it necessary for students to take a credit-bearing coursein intercultural communication that would be specifically designed to address the most typical problems that students might face when abroad, and to openly discuss their concerns before and during the sojourn. Given the fact that one third of the participants had had experiences abroad and yet still had worries and concerns about the coming SA, it is especially worthy to offer them a pre-sojourn program to better prepare them for the life and study abroad.

In addition, some studies have suggested that the sojourner's level of fluency in the language of the host country might influence his or her degree of adaptation to the new culture (Gullahorn \& Gullahorn 1966). Hence, to reduce their worries about being unable to communicate effectively with people from other cultures and/or having difficulty adapting to the local life, students on exchange programs need to improve their proficiency in the target language prior to their sojourn.

Acknowledgement: The present research was funded by the Direct Grant for Research 2010-11, first round, Chinese University of Hong Kong.

\section{References}

Allen, H. W. (2010). Language-learning motivation during short-term study abroad: an activity theory perspective. Foreign Language Annals, 43(1), 27-49.

Barkhuizen, G., \& Feryok, A. (2006): Pre-service Teachers' perceptions of a short-term international experience programme. Asia-Pacific Journal of Teacher Education, 34:1, 115-134.

Barron, A. (2007). “'Ah no honestly we're okay:' learning to upgrade in a study abroad context. Intercultural Pragmatics, 4-2, 129-166.

Bataller, R. (2010). Making a request for a service in Spanish: pragmatic development in the study abroad setting. Foreign Language Annals, 43(1), 160-175.

Berry, R. S. Y., \& Williams, M. (2004). Difficulties experienced by Hong Kong Chinese ESL learners at an independent school in the United Kingdom. Journal of Language and Social Psychology, 23, 118-134.

Cohen, A. D., \& Shively, R. L. (2007). Acquisition of requests and apologies in Spanish and French: impact of study abroad and strategy-building intervention: The Modern Language Journal, 91(2), 189-212. 
Collentine, J. (2004). The effects of learning contexts on morphosyntactic and lexical development. Studies in Second Language Acquisition, 26, 227-248.

DeKeyser, R. (2010). Monitoring processes in Spanish as a second language during a study abroad program. Foreign Language Annals, 43(1), 80-92.

Dewey, D. P. (2004). A comparison of reading development by learners of Japanese in intensive domestic immersion and study abroad contexts. SSLA, 26, 303-327.

Dewey, D. P. (2008). Japanese vocabulary acquisition by learners in three contexts. Frontiers: The Interdisciplinary Journal of Study Abroad, XV, 127-148.

Díaz-Campos, M. (2004). Context of learning in the acquisition of Spanish second language phonology. Studies in Second Language Acquisition, 26, 249-273.

Freed, B. F. (1999). An overview of issues and research in language learning in a study abroad setting. Frontiers: The Interdisciplinary Journal of $S A, 4,31-60$.

Freed, B., So, S., Lazar, N. (2003). Language learning abroad: how do gains in written fluency compare with gains in oral fluency in French as a second language? ADFL Bulletin, 34 (3), 34-40.

Grbich, C. (2007). Qualitative Data Analysis. London: SAGE Publications.

Gullahorn, J. E., \& Gullahorn, J. T. (1966). American students abroad: professional vs. personal development. Foreign Language Annals, 368, 43-59.

Hernández, T. A. (2010). The relationship among motivation, interaction, and the development of second language oral proficiency in a study-abroad context. The Modern Language Journal, 94(4), 600-617.

Huebner, T. (1998). Methodological considerations in data collection for language learning in a study abroad context. Frontiers: The Interdisciplinary Journal of Study Abroad, 4, 1-30.

Ife, A., Boix, G., \& Meara, P. (2000). The impact of study abroad on the vocabulary development of different proficiency groups. Spanish Applied Linguistics, 4, 55-84.

Isabelli-García, C. (2010). Acquisition of Spanish gender agreement in two learning contexts: study abroad and at home. Foreign Language Annals, 43 (2), 289-303.

Jackson, J. (2004). Language and cultural immersion: an ethnographic case study. Regional Language Center Journal, $35(3), 261-279$.

Jackson, J. (2010). IC Journeys: From Study to Residence Abroad. Hampshire, UK: Palgrave Macmillan.

Jackson, J. (2011). Cultivating cosmopolitan, intercultural citizenship through critical reflection and international, experiential learning. Language and Intercultural Communication, 11(2), 80-96.

Jarvis, H., \& Stakounis, H. (2010). Speaking in social contexts: issues for pre-sessional EAP students. TESL-EJ, 14(3), $1-14$.

Koester, J. (1986). A profile of foreign language majors who work, study, and travel abroad. The Modern Language Journal, 70(1), 21-27.

Lafford, B. A. (2004). The effect of the context of learning on the use of communication strategies by learners of Spanish as a second language. Studies in Second Language Acquisition, 26, 201-225.

Lennon, P. (1990). The advanced learner at large in the L2 community: developments in spoken performance.

International Review of Applied Linguistics, 28, 309-324.

Lindseth, M. U. (2010). The development of oral proficiency during a semester in Germany. Foreign Language Annals, 43(2), 246-268.

Llanes, A., \& Muñoz, C. (2009). A short stay abroad: does it make a difference? System, 37, 353-365.

Martinsen, R. A. (2011). Predicting changes in cultural sensitivity among students of Spanish during short-term study abroad. Hispania, 94(1), 121-141.

Milton, J., \& Meara, P. (1995). How periods abroad affect vocabulary growth in a foreign language. ITL Review of Applied Linguistics, 107-108, 17-34.

Mora, J. C. (2007). Learning context effects on the acquisition of a second language phonology. In C. Pérez-Vidal, M. Juan-Garau \& A. Bel (eds.), A portrait of the young in the new multilingual Spain (pp. 241-263). Clevedon:

Multilingual Matters.

Pérez-Vidal, C., \& Juan-Garau, M. (2011). The effect of context and input conditions on oral and written development: a study abroad perspective. IRAL, 49, 157-185.

Regan, V. (2004). The relationship between the group and the individual and the acquisition of native speaker variation patterns: a preliminary study. IRAL, 42: 335-348.

Segalowitz, N., \& Freed, B. F. (2004). Context, contact, and cognition in oral fluency acquisition: learning Spanish in at home and study abroad contexts. Studies in Second Language Acquisition, 26, 173-199.

Serrano, R., Llanes, Á., \& Tragant, E. (2011). Analyzing the effect of context of second language learning: domestic intensive and semi-intensive courses vs. study abroad in Europe. System, 39, 133-143.

Taguchi, N. (2008). Cognition, language contact, and the development of pragmatic comprehension in a study-abroad context. Language Learning, 58(1), 33-71.

Taillefer, G. F. (2005). Foreign language reading and study abroad: cross-cultural and cross-linguistic questions. The Modern Language Journal, 89(4), 503-528.

Takai, S. (1989). The adjustment of international students at a third culture-like academic community in Japan: a longitudinal study. Human Communication Studies, 17, 113-20. 
Trenchs-Parera, M. (2009). Effects of formal instruction and a stay abroad on the acquisition of native-like oral fluency. The Canadian Modern Language Review, 65(3), 365-393.

Wilkinson, S. (1998a). Study abroad from the participants' perspective: a challenge to common beliefs. Foreign Annals, 31 (1), 23-39.

Wilkinson, S. (1998b). On the nature of immersion during study abroad: some participant perspectives. Frontiers: The Interdisciplinary Journal of SA, 4, 121-138.

Xia, S. (2009). Are they ready to participate? East Asian students' acquisition of verbal participation in American classrooms. Issues in Applied Linguistics, 17(2), 137-157.

Xu, W., Case, R. E., \& Wang, Y. (2009). Pragmatic and grammatical competence, length of residence, and overall L2 proficiency. System, 37, 205-216.

Yashima, T., \& Zenuk-Nishide, L. (2008). The impact of learning contexts on proficiency, attitudes, and L2 communication: creating an imagined international community. System, 36, 566-585. 